\title{
Capsule Commentary on Goodwin et al., Receipt of Cancer Screening is a Predictor of Life Expectancy
}

\author{
Mara A. Schonberg, MD, MPH \\ Division of General Medicine and Primary Care, Department of Medicine, Harvard Medical School, Beth Israel Deaconess Medical Center, \\ Brookline, MA, USA.
}

J Gen Intern Med 31(11): 1354

DOI: $10.1007 / \mathrm{s} 11606-016-3824-\mathrm{x}$

(c) Society of General Internal Medicine 2016

$\mathrm{C}$ ancer screening among adults with $<10$ year life expectancy is increasingly being recognized as low-value care. ${ }^{1}$ Therefore, policy makers are interested in developing algorithms to identify and avoid low-value use of cancer screening among older adults. To identify older adults who receive low-value cancer screening, it is necessary to accurately estimate their life expectancy. Therefore, a previous study using Medicare claims data created and validated an algorithm to estimate beneficiary life expectancy based on beneficiary age, sex, and the presence of comorbidities. ${ }^{2}$ Ideally, this algorithm could now be used to help health systems identify low-value cancer screening among their older patients. However, Goodwin et al. ${ }^{3}$ in this manuscript identified an important limitation of using claims-based estimates of life expectancy.

Using data from a $5 \%$ sample of Medicare beneficiaries, aged 69-90 years by the end of 2002 (543,970 women and 362,753 men), Goodwin et al. examined the association of the receipt of screening mammography (in 2001/2002) or PSA (in 2002) on beneficiaries' overall survival through 2012. They found that women who underwent screening mammography lived around 2 years longer than women that did not get screened and men that received PSA screened lived around 1 year longer than those who were not screened. Of note, excluding beneficiaries diagnosed with cancer as a result of these tests did not affect the overall findings. However, since claims data do not capture beneficiaries' function, cognition, disease severity, or social support, and these factors affect receipt of cancer screening ${ }^{4}$, the prolonged survival associated with receipt of cancer screening among older adults is likely explained by these factors and probably reflects that providers are screening based on their judgement about patient's life expectancy.

Based on this study, it is important for policy makers to realize that claims-based estimates of life expectancy likely underestimate life expectancy among older adults receiving cancer screening. Therefore, using these measures could overestimate overuse of these tests. To overcome this limitation, policy makers could consider using shorter life expectancy estimates (e.g., 7 rather than 10 years) to identify low-value receipt of cancer screening among older adults.

Corresponding Author: Mara A. Schonberg, MD, MPH; Division of General Medicine and Primary Care, Department of Medicine, Harvard Medical School Beth Israel Deaconess Medical Center, 1309 Beacon, Office 219, Brookline, MA 02446, USA (e-mail: mschonbe@bidmc.harvard.edu).

Compliance with Ethical Standards:

Conflict of Interest: The author has no conflicts of interest with this article.

\section{REFERENCES}

1. Wilt TJ, Harris RP, Gaseem A. Screening for cancer: advice for high-value care from the American College of Physicians. Ann Intern Med. 2015;162(10):718-725.

2. Tan A, Kuo YF, Goodwin JS. Predicting life expectancy for communitydwelling older adults from Medicare claims data. Am J Epidemiol. 2013;178(6):974-983.

3. Goodwin JS, Sheffield K, Li S, Tan A. Receipt of cancer screening is a predictor of life expectancy. J Gen Intern Med. doi: 10.1007/s11606-0163787-y.

4. Schonberg MA, Breslau ES, McCarthy EP. Targeting of mammography screening according to life expectancy in women aged 75 and older. J Am Geriatr Soc. 2013.

Published online August 3, 2016 